\title{
Long Noncoding RNAs-Related Diseases, Cancers, and Drugs
}

\author{
Jen-Yang Tang, ${ }^{1,2,3}$ Jin-Ching Lee, ${ }^{4}$ Yung-Ting Chang, ${ }^{5}$ Ming-Feng Hou, ${ }^{3,6,7}$ \\ Hurng-Wern Huang, ${ }^{8}$ Chih-Chuang Liaw, ${ }^{5,9}$ and Hsueh-Wei Chang 3,10,11
}

${ }^{1}$ Department of Radiation Oncology, Faculty of Medicine, College of Medicine, Kaohsiung Medical University, Kaohsiung, Taiwan
${ }^{2}$ Department of Radiation Oncology, Kaohsiung Medical University Hospital, Kaohsiung, Taiwan
${ }^{3}$ Cancer Center, Kaohsiung Medical University Hospital, Kaohsiung Medical University, Kaohsiung, Taiwan
${ }^{4}$ Department of Biotechnology, Kaohsiung Medical University, Kaohsiung, Taiwan
${ }^{5}$ Doctor Degree Program in Marine Biotechnology, National Sun Yat-sen University/Academia Sinica, Kaohsiung, Taiwan
${ }^{6}$ Institute of Clinical Medicine, Kaohsiung Medical University, Kaohsiung, Taiwan
${ }^{7}$ Kaohsiung Municipal Ta-Tung Hospital, Kaohsiung, Taiwan
${ }^{8}$ Institute of Biomedical Science, National Sun Yat-Sen University, Kaohsiung, Taiwan
${ }^{9}$ Department of Marine Biotechnology and Resources, National Sun Yat-sen University, Kaohsiung, Taiwan
${ }^{10}$ Graduate Institute of Natural Products, Kaohsiung Medical University, Kaohsiung, Taiwan
${ }^{11}$ Department of Biomedical Science and Environmental Biology, Kaohsiung Medical University, Kaohsiung, Taiwan

Correspondence should be addressed to Chih-Chuang Liaw; ccliaw@mail.nsysu.edu.tw and

Hsueh-Wei Chang; changhw2007@gmail.com

Received 3 April 2013; Accepted 20 May 2013

Academic Editors: D. Benke, A. Capell, M. Ferracin, and M. Zarevucka

Copyright (C) 2013 Jen-Yang Tang et al. This is an open access article distributed under the Creative Commons Attribution License, which permits unrestricted use, distribution, and reproduction in any medium, provided the original work is properly cited.

Long noncoding RNA (lncRNA) function is described in terms of related gene expressions, diseases, and cancers as well as their polymorphisms. Potential modulators of lncRNA function, including clinical drugs, natural products, and derivatives, are discussed, and bioinformatic resources are summarized. The improving knowledge of the lncRNA regulatory network has implications not only in gene expression, diseases, and cancers, but also in the development of lncRNA-based pharmacology.

\section{Introduction}

Less than $2 \%$ of the mammalian genome is in proteinencoded regions, and the remainder is in noncoding RNAss (ncRNAs) [1]. Most long noncoding RNA (lncRNAs) are transcribed by RNA polymerase (Pol) II/Pol I, and some are transcribed by RNA Pol III [2]. The ncRNAs with nucleotide lengths of $<200$ and $>200$ are classified as short and long ncRNAs (lncRNAs), respectively. The lncRNAs can be further classified in terms of their orientation and location relative to neighboring genes as sense/antisense, divergent/convergent, and intronic/intergenic [3]. The lncRNAs function as chromatin scaffolds for complex assembly, as enhancers and decoys for improving and inhibiting transcription of target genes, and as cis-acting or trans-acting regulators of gene expression [4-6]. Cis-acting lncRNAs mediate local genes whereas trans-lncRNAs mediate multiple targets [6].
By dysregulating target gene expression, abnormal lncRNA expression causes cell dysfunction and disease progression. The official symbols of lncRNAs were designated by the HUGO Gene Nomenclature Committee [7].

\section{The lncRNAs and Gene Expressions}

The lncRNAs modulate cell cycle distribution and cell differentiation. For example, DNA damage-inducible lncRNA, namely, growth-arrested DNA damage-inducible gene 7 (gadd7), binds to TAR DNA-binding protein (TDP-43). By blocking the interaction between TDP-43 and cyclindependent kinase 6 (Cdk6) mRNA, gadd7 regulates cell cycle progression by promoting the decay of Cdk6 mRNA [17]. The lncRNAs reportedly modulate the differentiation of cells [18], the induction of pluripotent stem cell [19], and the induction of embryonic stem cells [20]. 
Some lncRNAs also have modulating effects on apoptosis [21]. For example, lncRNA, namely, erythroid prosurvival (EPS) is upregulated in terminal differentiation of murine erythroid cells [22] by inhibiting apoptosis [23]. Similarly, a study of melanoma cell lines showed that by downregulating sprouty homolog 4 intronic transcript 1 (SPRY4-IT1), lncRNAs inhibit cell proliferation and apoptosis [24].

In human cells, IncRNAs epigenetically regulate gene expression $[25,26]$ through chromatin remodeling [27]. For example, the mouse lncRNA, namely, potassium voltagegated channel, KQT-like subfamily, member 1 (KCNQ1) overlapping transcript 1 (Kcnqlotl) has a chromatin-interacting ability and can downregulate multiple genes in the Kcnq1 domain [28]. This gene silencing was reported to be mediated by DNA methylation at some target genes [29]. Other studies of cancer patients show that silenced tumor suppressor genes are often hypermethylated [30-32]. In the case of tumor suppressor genes, the epigenetic effect may have a role in carcinogenesis. In Hox antisense intergenic RNA (HOTAIR), long intergenic noncoding RNA (lincRNA), which is lncRNAs transcribed from noncoding DNA regions between protein-coding genes [33], may function as scaffolds for assembly of histone modification machinery [34].

Some lncRNAs may function through repeat sequences. For example, some lncRNAs that contain Alu elements [35] may transactivate Staufen 1- (STAU1-) mediated mRNA decay (SMD) by base pairing of Alu elements within both lncRNAs and $3^{\prime}$ untranslated region of the SMD target. These lncRNAs then downregulate several SMD targets [35].

\section{The lncRNAs and Diseases}

The functions of lncRNAs that are known to have roles in diseases have been reviewed previously [36, 37]. Recent studies suggest that lncRNAs have roles in neurodegenerative disorders [38, 39] and brain development [40]. In Huntington's disease, for example, neural lncRNAs are upregulated in taurine upregulated 1 (TUG1) and in nuclear paraspeckle assembly transcript 1 (NEAT1) but are downregulated in maternally expressed 3 (MEG3). The metastasis-associated lung adenocarcinoma transcript 1 (MALAT1) lncRNA is reportedly highly upregulated in neurons. In cultured hippocampal neurons, synaptic density is reduced by MALAT1 depletion but rescued by MALAT1 overexpression. Studies of patients with alcohol addiction reveal upregulated MALAT1 in the cerebellum, hippocampus, and brain stem [41], which suggests that the lncRNA network may have key roles in neurodegenerative processes [42].

Studies of patients with facioscapulohumeral muscular dystrophy (FSHD) involving Polycomb/Trithorax epigenetic regulation show a deregulated copy number in $\mathrm{D} 4 \mathrm{Z} 4$ repeat mapping to $4 \mathrm{q} 35$ [43]. A recent study of FSHD patients further showed that selective upregulation of DBE-T, a chromatin-associated lncRNA, reverses repression of 4q35 gene transcription [44]. These results suggest that lncRNAs derived from repetitive sequences may contribute to disease development through epigenetic regulation.

Recently, the single nucleotide polymorphisms (SNPs) of lncRNAs have been found to play important roles for disease association studies. For example, the SNP rs1333049 in the lncRNA, namely, antisense noncoding RNA in the INK4 locus (ANRIL) is reportedly associated with myocardial infarction as well as the pharmacogenomic evaluation in hypercholesterolemia [45]. SNP rs2383207 on lncRNAANRIL and SNP rs11066001 on protein-coded BRCA1 associated-protein (BRAP) gene were both associated with ankle-brachial index in a Taiwanese population [46]. Three SNPs (rs2067051, rs2251375, and rs4929984) located in $5^{\prime}$ region of the $\mathrm{H} 19$ imprinted maternally expressed transcript (H19) genes were reportedly associated with birth weight [47]. Additionally, the rs2839698 TC genotype of H19 was reportedly associated with a low risk for nonmuscle-invasive disease [48].

\section{The IncRNAs and Cancers}

Aberrant lncRNA expression contributes to tumor development in many cancer types [49-55]. For example, an lncRNA microarray showed that some lncRNAs contribute to glioma carcinogenesis $[56,57]$. The lncRNAs also have important roles in the development of lung [58], breast [59], and liver cancers [60].

The accumulating evidence of lncRNA involvement in carcinogenesis includes findings that downregulation of maternally expressed gene 3 (MEG3), an imprinted lncRNA, is associated with carcinogenesis of meningiomas [61] and bladder cancer [62]. The lncRNA, namely, ANRIL also contributes to the development of plexiform neurofibromas in neurofibromatosis type 1 [63]. The ANRIL downregulates tumor suppressor gene p15 (INK4B) expression by binding to and recruiting the suppressor of zeste 12 homolog (Drosophila) (SUZ12), a component of the Polycomb Repressive Complex 2 [64]. When DNA damage occurs, ANRIL is upregulated by the ATM-E2F1 signaling pathway [65].

In human colorectal cancer, lncRNA H19 and H19derived miR-675 are overexpressed in cell lines and primary tissues but not in adjacent noncancerous tissues [66]. Exogenous miR-675 expression also downregulates the tumor suppressor retinoblastoma, which is a direct target of miR-675 and increases tumor cell growth. Upregulation of H19 is also known to contribute to gastric cancer cell proliferation [67] and bladder cancer metastasis [68].

The HOTAIR is overexpressed in breast [69], nasopharyngeal [70], and liver [71] cancers. Loss of HOTAIR moderates the invasiveness of breast cancer, particularly in cells with upregulated Polycomb Repressive Complex 2 (PRC2). In nasopharyngeal and hepatocellular carcinoma, upregulated expression of HOTAIR indicates a poor prognosis [70, 71].

In lung cancer cells, downregulation of MALAT1 by siRNA decreases cell motility and downregulates motilityrelated genes [72], which suggests that MALAT1 promotes lung cancer metastasis. Similarly, MALAT1 is important in regulating cell proliferation, migration, and invasion of colorectal cancer metastasis [73]. In bladder cancer tissues, MALAT1 is overexpressed. Downregulation of MALAT1 by siRNA, the epithelial-to-mesenchymal transition-related genes, and cell migration of bladder cancer cells are inhibited [74]. After liver transplantation, MALAT1 is overexpressed 
in both cell lines and tissues of patients with hepatocellular carcinoma. Additionally, upregulated MALAT1 is associated with increased risk of liver tumor recurrence [75].

An lncRNA of highly upregulated liver cancer (HULC) is reportedly overexpressed in hepatocellular carcinoma [76]. The HULC may downregulate miR-372 and induce phosphorylation of cAMP responsive element binding protein 1 (CREB1) in liver cancer [77]. Similarly, overexpressed lncRNA, namely, urothelial carcinoma associated 1 (UCA1) affects cell proliferation and invasion in bladder cancer [78]. The CREB1 is involved in the UCA1-mediated cell cycle distribution of bladder cancer [79]. Another lncRNA, UCAla (cancer-upregulated drug-resistant gene, CUDR), reportedly regulates the carcinogenesis of human bladder cancer [80].

Methylation may also have a modulating role in lncRNA expression. For example, a study of triple-negative breast cancer cell lines showed hypermethylation and downregulation in both miR-31 and its MIR31 host gene (MIR31HG) [81]. The lncRNA, namely, colorectal neoplasia differentially expressed (CRNDE) is overexpressed in colorectal cancer and leukemia [82]. In esophageal adenocarcinoma, high-resolution methylome analyses have shown hypomethylated noncoding DNA regions and upregulated lncRNA in actin filament-associated protein 1 (AFAP1) antisense RNA 1 (AFAP1-AS1) [83].

Similar to the disease association studies as described above, the accumulating evidence of SNPs in lncRNAs has been reported in cancer association studies. For example, SNP array-based study reported that several SNPs in lncRNAs were associated with prostate cancer risk [84]. An lncRNA prostate cancer gene expression marker 1 (PCGEM1) is overexpressed in prostate cancer [85]. Two tagSNPs (rs6434568 and rs16834898) of the PCGEM1 were reported to be associated with prostate cancer [86]. Several lncRNAs contain SNPs such as rs7763881 in highly upregulated in liver cancer long noncoding RNA (HULC) and rs619586 in MALAT1 which are reportedly associated with decreased hepatocellular carcinoma risk [87].

\section{The lncRNAs and Their Potential Modulators}

Chemically engineered oligonucleotides that have proven effectivess for targeting endogenous miRNAs in mice [88] have potential applications in lncRNAs. For example, antisense oligonucleotides targeted at the mouse lncRNA Malat1 correct RNA gain-of-function effects of myotonic dystrophy [89]. Using siRNA treatment to lncRNA, the lncRNA, namely, antidifferentiation ncRNA (ANCR) is downregulated to promote osteoblast differentiation [90]. Similarly, siRNA-based downregulation of IncRNA associated with liver regeneration (LALR1) inhibits hepatocyte proliferation and cell cycle progression during liver regeneration [91]. Data obtained by a recent systematic transcriptome-wide analysis of lncRNAmiRNA interactions [92] may reveal additional regulators of IncRNA expression such as miRNAs that contribute to lncRNA degeneration. For example, in some lncRNAs targeted by breast cancer-related miRNAs, changes in gene expressions differ between women with and without breast tumors [93].
Inhibitors that modulate lncRNA function have also been identified. For example, small molecules such as diazobenzene-related compounds are now known to inhibit the function of miR-21 [94], a polyadenylated lncRNA [95]. 5-aza-2 ${ }^{\prime}$-deoxycytidine (5-aza-dC), a methylation inhibitor, inhibits the methylation of putative imprinted control region (ICR) of H19 gene and leads to the downregulation of the H19 mRNA expression in blastocysts derived from vitrified twocell embryos [96]. This finding suggests that epigenetic agents may be the modulators for lncRNA expression as well as their related targeting signals.

The hypothesis that environmental exposures are another cause of ncRNA alterations [97] was tested by exposing aquatic midges to xenobiotics, which revealed upregulation of $\operatorname{lncRNAs}$ derived from repetitive sequences [98]. Additionally, telomeric and centromeric ncRNA can be activated by bisphenol A, a synthetic chemical with estrogen-like effects [98]. Based on these findings, some drugs may also modulate lncRNA expression. Therefore, many natural products and their derivatives are likely to prove suitable for screening and identifying these modulators in lncRNAs.

\section{Long Noncoding RNA and Bioinformatics Resources}

Computational methods for predicting lncRNA function have been well reviewed [99]. Recently, consistently improving computational capability enabled rapid development of functional analyses and bioinformatics resources for $\operatorname{lncR}$ NAs [100]. Except for NRED [8], ncFANs [9], and lncRNAdb [10], we summarize the update progression of bioinformatics resources for lncRNAs during 2012-2013 as shown in Table 1.

For example, the NRED [8] database of lncRNA expression includes both microarray and in situ hybridization data for human and mouse lncRNAs. The noncoding RNA Function Anotation server (ncFANs) [9], a web server for functional anotation of lncRNAs, includes ten reannotated human and mouse microarray datasets. The lncRNAdb [10] is a comprehensive database of eukaryotic lncRNA anotations. The data contained in the lncRNAdb include sequences, structures, genomic contexts, expressions, and subcellular distributions. Most ( 75\%) lncRNAs in the database were collected from mammals.

The NONCODE v3.0 [11] is an integrated database of lncRNA anotations obtained from re-annotated and updated microarray data from NONCODE v2.0 [101]. The NONCODE v3.0 database includes a visualized Genome Browser and a BLAST-based sequence alignment search. Since the secondary structure of an lncRNA may affect its protein interactions, the LNCipedia [12] provides helpful information for visualizing the structures of annotated lncRNA sequences. The LNCipedia also uses an algorithm for predicting potential coding scores for each transcript and an HMMER algorithm for searching for RNA sequences in Pfam protein domains. The LncRNADisease [102] provides experimentally validated $\operatorname{lncRNA}$-disease associations for 166 diseases in curated lncRNA interacting partners at the protein, RNA, miRNA, and DNA levels. Similarly, DIANA-LncBase provides experimentally verified and computationally predicted 
TABLE 1: The lncRNA bioinformatics resources.

\begin{tabular}{ll}
\hline Name & Description \\
\hline NRED [8] & Database of lncRNA expression. (http://nred.matticklab.com/cgi-bin/ncrnadb.pl/) \\
ncFANs [9] & Web server for functional annotation of lncRNAs. (http://ebiomed.org/ncfans/) \\
lncRNAdb [10] & Database of comprehensive annotations of functional lncRNAs. (http://www.lncrnadb.org/) \\
NONCODE [11] & Database of integrative annotations of lncRNAs. (http://www.noncode.org/NONCODERv3/guide.htm) \\
LNCipedia [12] & Database of annotations and structures of lncRNA sequences. (http://www.lncipedia.org/) \\
LncRNADisease [13] & $\begin{array}{l}\text { Database of lncRNA-associated diseases. (http://cmbi.bjmu.edu.cn/lncrnadisease/) } \\
\text { DIANA-LncBase [14] }\end{array}$ \\
$\begin{array}{l}\text { Database of microRNA targets on lncRNAs. (http://www.microrna.gr/LncBase/) } \\
\text { iSeeRNA [15] }\end{array}$ & $\begin{array}{l}\text { (http://www.myogenesisdb.org/iSeeRNA/) } \\
\text { Database for annotating and exploring the expression profiles in transcriptional regulation of lncRNAs and } \\
\text { other ncRNAs. (http://deepbase.sysu.edu.cn/chipbase/) }\end{array}$ \\
ChIPBase [16] &
\end{tabular}

miRNA target sites of human and mouse lncRNAs [14]. The iSeeRNA [15] webserver was constructed by using a support vector machine- (SVM-) based classifier to identify lincRNAs from transcriptome sequencing data. Based on next-generation sequencing (ChIP-Seq) data, ChIPBase [16] provides anotations and identifyies information for transcription factor binding sites (TFBS) of lncRNAs and miRNAs from chromatin immunoprecipitation. A database of the regulatory relationships of transcription factors/lncRNA and transcription factors/miRNA is also being considered.

\section{Conclusion}

Various lncRNA functions are essential for regulating gene expression. This study focused on lncRNA dysregulation associated with disease progression and carcinogenesis and on the development of drugs for modulating lncRNA function. Since lncRNA is rarely studied in natural products, the resources mentioned in the paper may provide helpful information for researchers studying natural products.

\section{Acknowledgments}

This study was supported by a Grant from the National Science Council (NSC101-2320-B-037-049), the Department of Health, Executive Yuan, Republic of China (DOH102TD-C-111-002), the Kaohsiung Medical University Research Foundation (KMUER001), and the National Sun Yat-Sen University-KMU Joint Research Project (no. NSYSU-KMU 102-034).

\section{References}

[1] Y. Hayashizaki, "Molecular biology: the transcriptional landscape of the mammalian genome," Science, vol. 309, no. 5740, pp. 1559-1563, 2005.

[2] H. Bierhoff, K. Schmitz, F. Maass, J. Ye, and I. Grummt, "Noncoding transcripts in sense and antisense orientation regulate the epigenetic state of ribosomal RNA genes," Cold Spring Harbor Symposia on Quantitative Biology, vol. 75, pp. 357-364, 2010.
[3] J. L. Rinn and H. Y. Chang, "Genome regulation by long noncoding RNAs," Annual Review of Biochemistry, vol. 81, pp. 145-166, 2012.

[4] K. C. Wang and H. Y. Chang, "Molecular mechanisms of long noncoding RNAs," Molecular Cell, vol. 43, no. 6, pp. 904-914, 2011.

[5] U. A. Ørom and R. Shiekhattar, "Long non-coding RNAs and enhancers," Current Opinion in Genetics \& Development, vol. 21, no. 2, pp. 194-198, 2011.

[6] T. Nagano and P. Fraser, "No-nonsense functions for long noncoding RNAs," Cell, vol. 145, no. 2, pp. 178-181, 2011.

[7] M. W. Wright and E. A. Bruford, "Naming "junk": human nonprotein coding RNA (ncRNA) gene nomenclature," Human Genomics, vol. 5, no. 2, pp. 90-98, 2011.

[8] M. E. Dinger, K. C. Pang, T. R. Mercer, M. L. Crowe, S. M. Grimmond, and J. S. Mattick, "NRED: a database of long noncoding RNA expression," Nucleic Acids Research, vol. 37, no. 1, pp. D122-D126, 2009.

[9] Q. Liao, H. Xiao, D. Bu et al., "NcFANs: a web server for functional annotation of long non-coding RNAs," Nucleic Acids Research, vol. 39, no. 2, pp. W118-W124, 2011.

[10] P. P. Amaral, M. B. Clark, D. K. Gascoigne, M. E. Dinger, and J. S. Mattick, "LncRNAdb: a reference database for long noncoding RNAs," Nucleic Acids Research, vol. 39, pp. D146-D151, 2011.

[11] D. Bu, K. Yu, S. Sun et al., "NONCODE v3. 0: integrative annotation of long noncoding RNAs," Nucleic Acids Research, vol. 40, pp. 210-215, 2012.

[12] P. J. Volders, K. Helsens, X. Wang et al., "LNCipedia: a database for annotated human IncRNA transcript sequences and structures," Nucleic Acids Research, vol. 41, pp. D246-D251, 2013.

[13] X. M. Fernandez-Suarez and M. Y. Galperin, "The 2013 nucleic acids research database issue and the online molecular biology database collection," Nucleic Acids Research, vol. 41, pp. D1-D7, 2013.

[14] M. D. Paraskevopoulou, G. Georgakilas, N. Kostoulas et al., "DIANA-LncBase: experimentally verified and computationally predicted microRNA targets on long non-coding RNAs," Nucleic Acids Research, vol. 41, pp. D239-D245, 2013.

[15] K. Sun, X. Chen, P. Jiang, X. Song, H. Wang, and H. Sun, "iSeeRNA: identification of long intergenic non-coding RNA transcripts from transcriptome sequencing data," BMC Genomics, vol. 14, supplement 2, article S7, 2013. 
[16] J. H. Yang, J. H. Li, S. Jiang, H. Zhou, and L. H. Qu, "ChIPBase: a database for decoding the transcriptional regulation of long non-coding RNA and microRNA genes from ChIP-Seq data," Nucleic Acids Research, vol. 41, pp. D177-D187, 2013.

[17] X. Liu, D. Li, W. Zhang, M. Guo, and Q. Zhan, "Long noncoding RNA gadd7 interacts with TDP-43 and regulates Cdk6 mRNA decay," The EMBO Journal, vol. 31, no. 23, pp. 4415-4427, 2012.

[18] W. Hu, J. R. Alvarez-Dominguez, and H. F. Lodish, "Regulation of mammalian cell differentiation by long non-coding RNAs," EMBO Reports, vol. 13, no. 11, pp. 971-983, 2012.

[19] J. S. Huo and E. T. Zambidis, "Pivots of pluripotency: the roles of non-coding RNA in regulating embryonic and induced pluripotent stem cells," Biochimica et Biophysica Acta, vol. 1830, no. 2, pp. 2385-2394, 2013.

[20] A. A. Sigova, A. C. Mullen, B. Molinie et al., "Divergent transcription of long noncoding RNA/mRNA gene pairs in embryonic stem cells," Proceedings of the National Academy of Sciences of the United States of America, vol. 110, no. 8, pp. 28762881, 2013.

[21] S. C. Lakhotia, "Long non-coding RNAs coordinate cellular responses to stress," Wiley Interdisciplinary Reviews, vol. 3, no. 6, pp. 779-796, 2012.

[22] W. Hu, B. Yuan, J. Flygare, and H. F. Lodish, "Long noncoding RNA-mediated anti-apoptotic activity in murine erythroid terminal differentiation," Genes and Development, vol. 25, no. 24, pp. 2573-2578, 2011.

[23] V. R. Paralkar and M. J. Weiss, "A new "Linc" between noncoding RNAs and blood development," Genes and Development, vol. 25, no. 24, pp. 2555-2558, 2011.

[24] D. Khaitan, M. E. Dinger, J. Mazar et al., "The melanomaupregulated long noncoding RNA SPRY4-IT1 modulates apoptosis and invasion," Cancer Research, vol. 71, no. 11, pp. 3852$3862,2011$.

[25] K. V. Morris, "Long antisense non-coding RNAs function to direct epigenetic complexes that regulate transcription in human cells," Epigenetics, vol. 4, no. 5, pp. 296-301, 2009.

[26] J. T. Lee, "Epigenetic regulation by long noncoding RNAs," Science, vol. 338, no. 6113, pp. 1435-1439, 2012.

[27] A. Saxena and P. Carninci, "Long non-coding RNA modifies chromatin: epigenetic silencing by long non-coding RNAs," BioEssays, vol. 33, no. 11, pp. 830-839, 2011.

[28] C. Kanduri, "Kcnqlotl: a chromatin regulatory RNA," Seminars in Cell and Developmental Biology, vol. 22, no. 4, pp. 343-350, 2011.

[29] F. Mohammad, G. K. Pandey, T. Mondal et al., "Long noncoding RNA-mediated maintenance of DNA methylation and transcriptional gene silencing," Development, vol. 139, no. 15, pp. 2792-2803, 2012.

[30] B. Jin and K. D. Robertson, "DNA methyltransferases, DNA damage repair, and cancer," Advances in Experimental Medicine and Biology, vol. 754, pp. 3-29, 2013.

[31] K. K. Li, F. Li, Q. S. Li, K. Yang, and B. Jin, "DNA methylation as a target of epigenetic therapeutics in cancer," Anticancer Agents in Medicinal Chemistry, vol. 13, no. 2, pp. 242-247, 2013.

[32] X. T. Hu and C. He, "Recent progress in the study of methylated tumor suppressor genes in gastric cancer," Chinese Journal of Cancer, vol. 32, no. 1, pp. 31-41, 2013.

[33] V. A. Moran, R. J. Perera, and A. M. Khalil, "Emerging functional and mechanistic paradigms of mammalian long noncoding RNAs," Nucleic Acids Research, vol. 40, no. 14, pp. 6391$6400,2012$.
[34] M. Tsai, O. Manor, Y. Wan et al., "Long noncoding RNA as modular scaffold of histone modification complexes," Science, vol. 329, no. 5992, pp. 689-693, 2010.

[35] C. Gong and L. E. Maquat, "LncRNAs transactivate STAU1mediated mRNA decay by duplexing with 39 UTRs via Alu elements," Nature, vol. 470, no. 7333, pp. 284-288, 2011.

[36] O. Wapinski and H. Y. Chang, "Long noncoding RNAs and human disease," Trends in Cell Biology, vol. 21, no. 6, pp. 354361, 2011.

[37] L. W. Harries, "Long non-coding RNAs and human disease," Biochemical Society Transactions, vol. 40, no. 4, pp. 902-906, 2012.

[38] E. Salta and B. De Strooper, "Non-coding RNAs with essential roles in neurodegenerative disorders," The Lancet Neurology, vol. 11, no. 2, pp. 189-200, 2012.

[39] I. A. Qureshi, J. S. Mattick, and M. F. Mehler, "Long non-coding RNAs in nervous system function and disease," Brain Research, vol. 1338, pp. 20-35, 2010.

[40] I. A. Qureshi and M. F. Mehler, "Emerging roles of non-coding RNAs in brain evolution, development, plasticity and disease," Nature Reviews Neuroscience, vol. 13, no. 8, pp. 528-541, 2012.

[41] R. Kryger, L. Fan, P. A. Wilce, and V. Jaquet, "MALAT-1, a non protein-coding RNA is upregulated in the cerebellum, hippocampus and brain stem of human alcoholics," Alcohol, vol. 46, no. 7, pp. 629-634, 2012.

[42] R. Johnson, "Long non-coding RNAs in Huntington's disease neurodegeneration," Neurobiology of Disease, vol. 46, no. 2, pp. 245-254, 2012.

[43] D. S. Cabianca, V. Casa, and D. Gabellini, "A novel molecular mechanism in human genetic disease: a DNA repeat-derived lncRNA," RNA Biology, vol. 9, no. 10, pp. 1211-1217, 2012.

[44] D. Cabianca, V. Casa, B. Bodega et al., "A long ncRNA links copy number variation to a polycomb/trithorax epigenetic switch in FSHD muscular dystrophy," Cell, vol. 149, no. 4, pp. 819-831, 2012.

[45] W. Ahmed, I. S. Ali, M. Riaz et al., "Association of ANRIL polymorphism (rs1333049: C > G) with myocardial infarction and its pharmacogenomic role in hypercholesterolemia," Gene, vol. 515, no. 2, pp. 416-420, 2013.

[46] P. Tsai, Y. Liao, T. Lin, E. Hsi, Y. Yang, and S. H. Juo, "Additive effect of ANRIL and BRAP polymorphisms on ankle-brachial index in a Taiwanese population," Circulation Journal, vol. 76, no. 2, pp. 446-452, 2012.

[47] R. M. Adkins, G. Somes, J. C. Morrison et al., "Association of birth weight with polymorphisms in the IGF2, H19, and IGF2R genes," Pediatric Research, vol. 68, no. 5, pp. 429-434, 2010.

[48] G. W. Verhaegh, L. Verkleij, S. H. H. M. Vermeulen, M. den Heijer, J. A. Witjes, and L. A. Kiemeney, "Polymorphisms in the H19 gene and the risk of bladder cancer," European Urology, vol. 54, no. 5, pp. 1118-1126, 2008.

[49] J. M. Silva, D. S. Perez, J. R. Pritchett, M. L. Halling, H. Tang, and D. I. Smith, "Identification of long stress-induced non-coding transcripts that have altered expression in cancer," Genomics, vol. 95, no. 6, pp. 355-362, 2010.

[50] K. V. Morris and P. K. Vogt, "Long antisense non-coding RNAs and their role in transcription and oncogenesis," Cell Cycle, vol. 9, no. 13, pp. 2544-2547, 2010.

[51] J. R. Prensner and A. M. Chinnaiyan, "The emergence of lncRNAs in cancer biology," Cancer Discovery, vol. 1, no. 5, pp. 391-407, 2011. 
[52] E. A. Gibb, C. J. Brown, and W. L. Lam, "The functional role of long non-coding RNA in human carcinomas," Molecular Cancer, vol. 10, article 38, 2011.

[53] F. Yang, F. Yi, Z. Zheng et al., "Characterization of a carcinogenesis-associated long non-coding RNA," RNA Biology, vol. 9, no. 1, pp. 110-116, 2012.

[54] M. Kitagawa, Y. Kotake, and T. Ohhata, "Long non-coding RNAs involved in cancer development and cell fate determination," Current Drug Targets, vol. 13, no. 13, pp. 1616-1621, 2012.

[55] N. Hauptman and D. Glavac, "Long non-coding RNA in cancer," International Journal of Molecular Sciences, vol. 14, no. 3, pp. 4655-4669, 2013.

[56] L. Han, K. Zhang, Z. Shi et al., "LncRNA profile of glioblastoma reveals the potential role of lncRNAs in contributing to glioblastoma pathogenesis," International Journal of Oncology, vol. 40, no. 6, pp. 2004-2012, 2012.

[57] X. Zhang, S. Sun, J. K. Pu et al., "Long non-coding RNA expression profiles predict clinical phenotypes in glioma," Neurobiology of Disease, vol. 48, no. 1, pp. 1-8, 2012.

[58] K. S. Enfield, L. A. Pikor, V. D. Martinez, and W. L. Lam, "Mechanistic roles of noncoding RNAs in lung cancer biology and their clinical implications," Genetics Research International, vol. 2012, Article ID 737416, 16 pages, 2012.

[59] H. Piao and L. Ma, "Non-coding RNAs as regulators of mammary development and breast cancer," Journal of Mammary Gland Biology and Neoplasia, vol. 17, no. 1, pp. 33-42, 2012.

[60] F. Yang, L. Zhang, X. Huo et al., "Long noncoding RNA high expression in hepatocellular carcinoma facilitates tumor growth through enhancer of zeste homolog 2 in humans," Hepatology, vol. 54, no. 5, pp. 1679-1689, 2011.

[61] X. Zhang, R. Gejman, A. Mahta et al., "Maternally expressed gene 3, an imprinted noncoding RNA gene, is associated with meningioma pathogenesis and progression," Cancer Research, vol. 70, no. 6, pp. 2350-2358, 2010.

[62] L. Ying, Y. Huang, H. Chen et al., "Downregulated MEG3 activates autophagy and increases cell proliferation in bladder cancer," Molecular BioSystems, vol. 9, no. 3, pp. 407-411, 2013.

[63] O. Dereure, "Role of non-coding RNA ANRIL in the genesis of plexiform neurofibromas in neurofibromatosis type 1," Annales de Dermatologie et de Venereologie, vol. 139, no. 5, pp. 421-422, 2012.

[64] Y. Kotake, T. Nakagawa, K. Kitagawa et al., "Long non-coding RNA ANRIL is required for the PRC2 recruitment to and silencing of p15 INK4B tumor suppressor gene," Oncogene, vol. 30, no. 16, pp. 1956-1962, 2011.

[65] G. Wan, R. Mathur, X. Hu et al., "Long non-coding RNA ANRIL (CDKN2B-AS) is induced by the ATM-E2F1 signaling pathway," Cell Signal, vol. 25, no. 5, pp. 1086-1095, 2013.

[66] W. P. Tsang, E. K. O. Ng, S. S. M. Ng et al., "Oncofetal H19derived miR-675 regulates tumor suppressor RB in human colorectal cancer," Carcinogenesis, vol. 31, no. 3, pp. 350-358, 2010.

[67] F. Yang, J. Bi, X. Xue et al., "Up-regulated long non-coding RNA H19 contributes to proliferation of gastric cancer cells," FEBS Journal, vol. 279, no. 17, pp. 3159-3165, 2012.

[68] M. Luo, Z. Li, W. Wang, Y. Zeng, Z. Liu, and J. Qiu, "Long non-coding RNA H19 increases bladder cancer metastasis by associating with EZH2 and inhibiting E-cadherin expression," Cancer Letters, vol. 333, no. 2, pp. 213-221, 2013.

[69] R. A. Gupta, N. Shah, K. C. Wang et al., "Long non-coding RNA HOTAIR reprograms chromatin state to promote cancer metastasis," Nature, vol. 464, no. 7291, pp. 1071-1076, 2010.
[70] Y. Nie, X. Liu, S. Qu, E. Song, H. Zou, and C. Gong, "Long noncoding RNA HOTAIR is an independent prognostic marker for nasopharyngeal carcinoma progression and survival," Cancer Science, vol. 104, no. 4, pp. 458-464, 2013.

[71] M. Ishibashi, R. Kogo, K. Shibata et al., "Clinical significance of the expression of long non-coding RNA HOTAIR in primary hepatocellular carcinoma," Oncology Reports, vol. 29, no. 3, pp. 946-950, 2013.

[72] K. Tano, R. Mizuno, T. Okada et al., "MALAT-1 enhances cell motility of lung adenocarcinoma cells by influencing the expression of motility-related genes," FEBS Letters, vol. 584, no. 22, pp. 4575-4580, 2010.

[73] C. Xu, M. Yang, J. Tian, X. Wang, and Z. Li, "MALAT-1: a long non-coding RNA and its important 3' end functional motif in colorectal cancer metastasis," International Journal of Oncology, vol. 39, no. 1, pp. 169-175, 2011.

[74] L. Ying, Q. Chen, Y. Wang, Z. Zhou, Y. Huang, and F. Qiu, "Upregulated MALAT-1 contributes to bladder cancer cell migration by inducing epithelial-to-mesenchymal transition," Molecular BioSystems, vol. 8, no. 9, pp. 2289-2294, 2012.

[75] M. Lai, Z. Yang, L. Zhou et al., "Long non-coding RNA MALAT1 overexpression predicts tumor recurrence of hepatocellular carcinoma after liver transplantation," Medical Oncology, vol. 29, no. 3, pp. 1810-1816, 2012.

[76] K. Panzitt, M. M. O. Tschernatsch, C. Guelly et al., "Characterization of HULC, a novel gene with striking up-regulation in hepatocellular carcinoma, as noncoding RNA," Gastroenterology, vol. 132, no. 1, pp. 330-342, 2007.

[77] J. Wang, X. Liu, H. Wu et al., "CREB up-regulates long non-coding RNA, HULC expression through interaction with microRNA-372 in liver cancer," Nucleic Acids Research, vol. 38, no. 16, pp. 5366-5383, 2010.

[78] F. Wang, X. Li, X. Xie, L. Zhao, and W. Chen, "UCA1, a nonprotein-coding RNA up-regulated in bladder carcinoma and embryo, influencing cell growth and promoting invasion," FEBS Letters, vol. 582, no. 13, pp. 1919-1927, 2008.

[79] C. Yang, X. Li, Y. Wang, L. Zhao, and W. Chen, "Long noncoding RNA UCA1 regulated cell cycle distribution via CREB through PI3-K dependent pathway in bladder carcinoma cells," Gene, vol. 496, no. 1, pp. 8-16, 2012.

[80] Y. Wang, W. Chen, C. Yang et al., "Long non-coding RNA UCAla (CUDR) promotes proliferation and tumorigenesis of bladder cancer," International Journal of Oncology, vol. 41, no. 1, pp. 276-284, 2012.

[81] K. Augoff, B. McCue, E. F. Plow, and K. Sossey-Alaoui, "MiR31 and its host gene IncRNA LOC554202 are regulated by promoter hypermethylation in triple-negative breast cancer," Molecular Cancer, vol. 11, article 5, 2012.

[82] B. C. Ellis, P. L. Molloy, and L. D. Graham, "CRNDE: a long non-coding RNA involved in cancer, neurobiology, and development," Frontiers in Genetics, vol. 3, article 270, 2012.

[83] W. Wu, T. D. Bhagat, X. Yang et al., "Hypomethylation of noncoding DNA regions and overexpression of the long noncoding RNA, AFAP1-AS1, in Barrett's esophagus and esophageal adenocarcinoma," Gastroenterology, vol. 144, no. 5, pp. 956.e4966.e4, 2013.

[84] G. Jin, J. Sun, S. D. Isaacs et al., "Human polymorphisms at long non-coding RNAs (lncRNAs) and association with prostate cancer risk," Carcinogenesis, vol. 32, no. 11, pp. 1655-1659, 2011.

[85] X. Fu, L. Ravindranath, N. Tran, G. Petrovics, and S. Srivastava, "Regulation of apoptosis by a prostate-specific and prostate 
cancer-associated noncoding gene, PCGEM1, DNA and Cell Biology, vol. 25, no. 3, pp. 135-141, 2006.

[86] Y. Xue, M. Wang, M. Kang et al., "Association between lncrna PCGEM1 polymorphisms and prostate cancer risk," Prostate Cancer and Prostatic Diseases, vol. 16, no. 2, pp. 139-144, 2013.

[87] Y. Liu, S. Pan, L. Liu et al., "A genetic variant in long non-coding RNA HULC contributes to risk of HBV-related hepatocellular carcinoma in a chinese population," PLOS ONE, vol. 7, no. 4, Article ID e35145, 2012.

[88] J. Krützfeldt, N. Rajewsky, R. Braich et al., "Silencing of microRNAs in vivo with 'antagomirs"' Nature, vol. 438, no. 7068, pp. 685-689, 2005.

[89] T. M. Wheeler, A. J. Leger, S. K. Pandey et al., "Targeting nuclear RNA for in vivo correction of myotonic dystrophy," Nature, vol. 488, no. 7409, pp. 111-115, 2012.

[90] L. Zhu and P. C. Xu, "Downregulated LncRNA-ANCR promotes osteoblast differentiation by targeting EZH2 and regulating Runx2 expression," Biochemical and Biophysical Research Communications, vol. 432, no. 4, pp. 612-617, 2013.

[91] D. Xu, F. Yang, J. H. Yuan et al., "LncRNA-LALR1 accelerates hepatocyte proliferation during liver regeneration by activating Wnt/beta-Catenin signaling," Hepatology, 2013.

[92] S. Jalali, D. Bhartiya, M. K. Lalwani, S. Sivasubbu, and V. Scaria, "Systematic transcriptome wide analysis of lncRNA-miRNA interactions," PLoS ONE, vol. 8, no. 2, Article ID e53823, 2013.

[93] L. Juan, G. Wang, M. Radovich et al., "Potential roles of microRNAs in regulating long intergenic noncoding RNAs," $B M C$ Med Genomics, vol. 6, supplement 1, article S7, 2013.

[94] K. Gumireddy, D. D. Young, X. Xiong, J. B. Hogenesch, Q. Huang, and A. Deiters, "Small-molecule inhibitors of microRNA miR-21 function," Angewandte Chemie, vol. 47, no. 39, pp. 7482-7484, 2008.

[95] X. Cai, C. H. Hagedorn, and B. R. Cullen, "Human microRNAs are processed from capped, polyadenylated transcripts that can also function as mRNAs," RNA, vol. 10, no. 12, pp. 1957-1966, 2004.

[96] X. M. Zhao, J. J. Ren, W. H. Du et al., "Effect of 5-aza-2'deoxycytidine on methylation of the putative imprinted control region of $\mathrm{H19}$ during the in vitro development of vitrified bovine two-cell embryos," Fertility and Sterility, vol. 98, no. 1, pp. 222227, 2012.

[97] M. A. Maccani and V. S. Knopik, "Cigarette smoke exposureassociated alterations to non-coding RNA," Frontiers in Genetics, vol. 3, article 53, 2012.

[98] J. Martínez-Guitarte, R. Planelló, and G. Morcillo, “Overexpression of long non-coding RNAs following exposure to xenobiotics in the aquatic midge Chironomus riparius," Aquatic Toxicology, vol. 110-111, pp. 84-90, 2012.

[99] H. Ma, Y. Hao, X. Dong et al., "Molecular mechanisms and function prediction of long noncoding RNA," The Scientific World Journal, vol. 2012, Article ID 541786, 11 pages, 2012.

[100] L. da Sacco, A. Baldassarre, and A. Masotti, "Bioinformatics tools and novel challenges in long non-coding RNAs (lncRNAs) functional analysis," International Journal of Molecular Sciences, vol. 13, no. 1, pp. 97-114, 2012.

[101] S. He, C. Liu, G. Skogerbø et al., "NONCODE v2.0: decoding the non-coding," Nucleic Acids Research, vol. 36, no. 1, pp. D170D172, 2008.

[102] G. Chen, Z. Wang, D. Wang et al., "LncRNA disease: a database for long-non-coding RNA-associated diseases," Nucleic Acids Research, vol. 41, pp. D983-D986, 2013. 

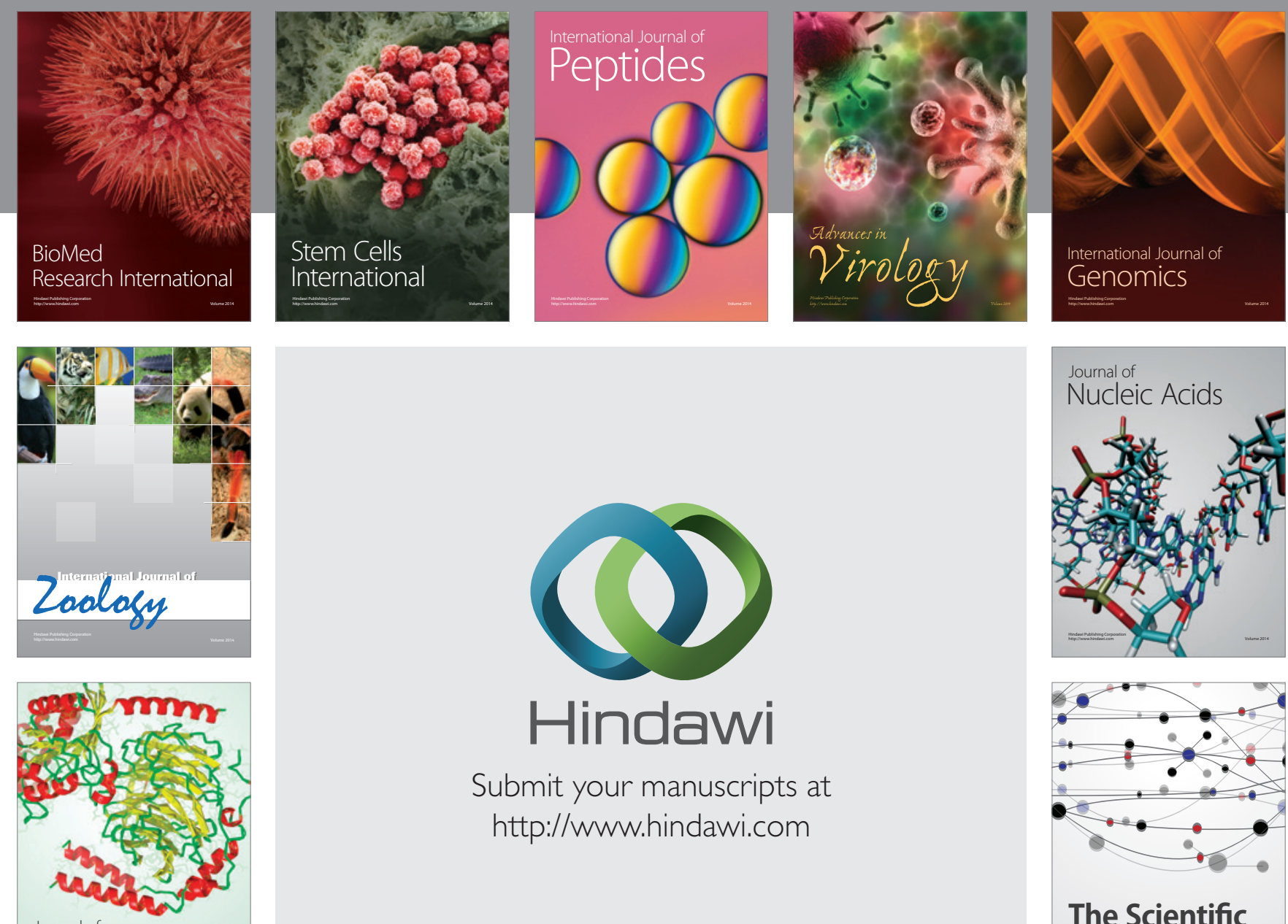

Submit your manuscripts at

http://www.hindawi.com

Journal of
Signal Transduction
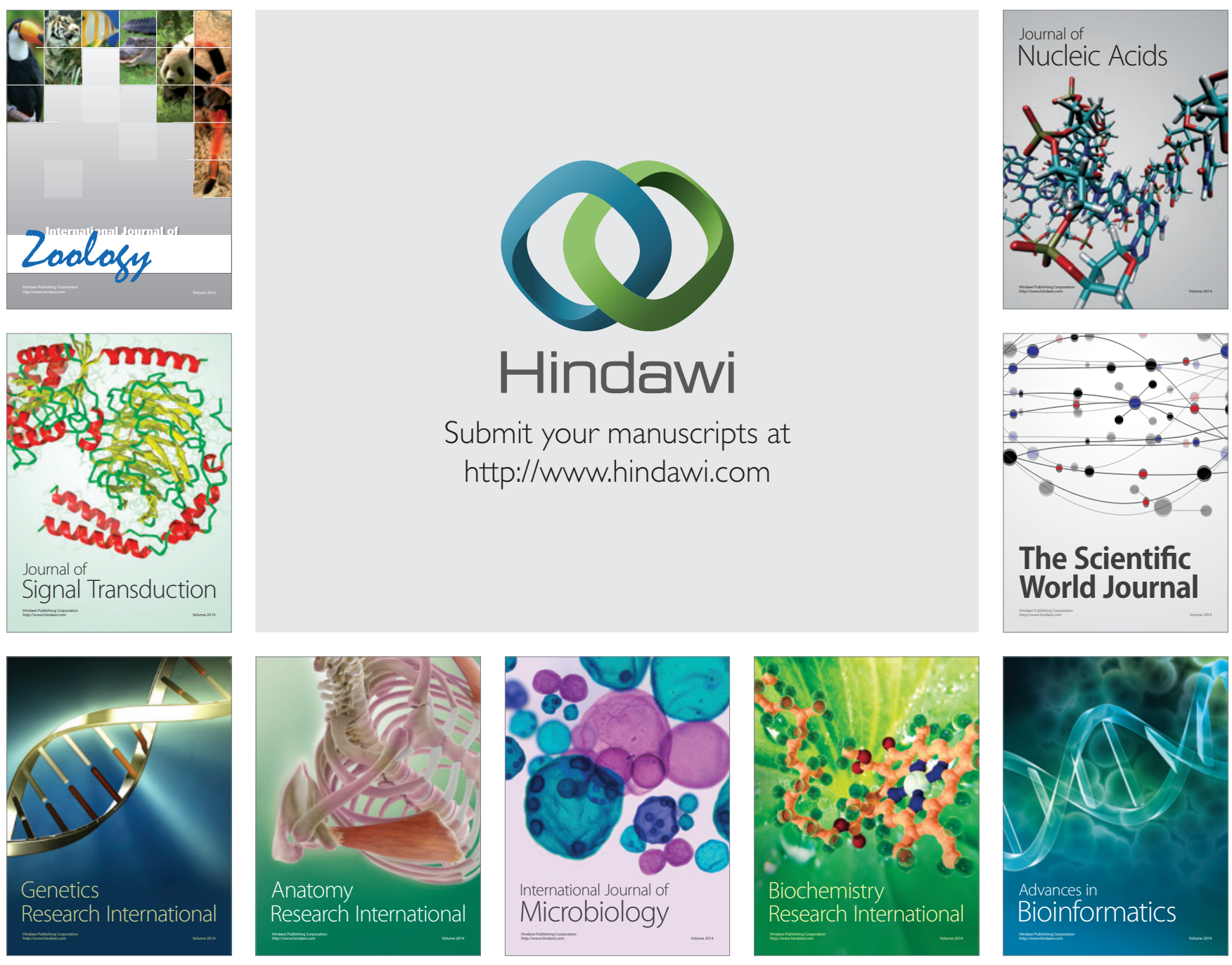

The Scientific World Journal
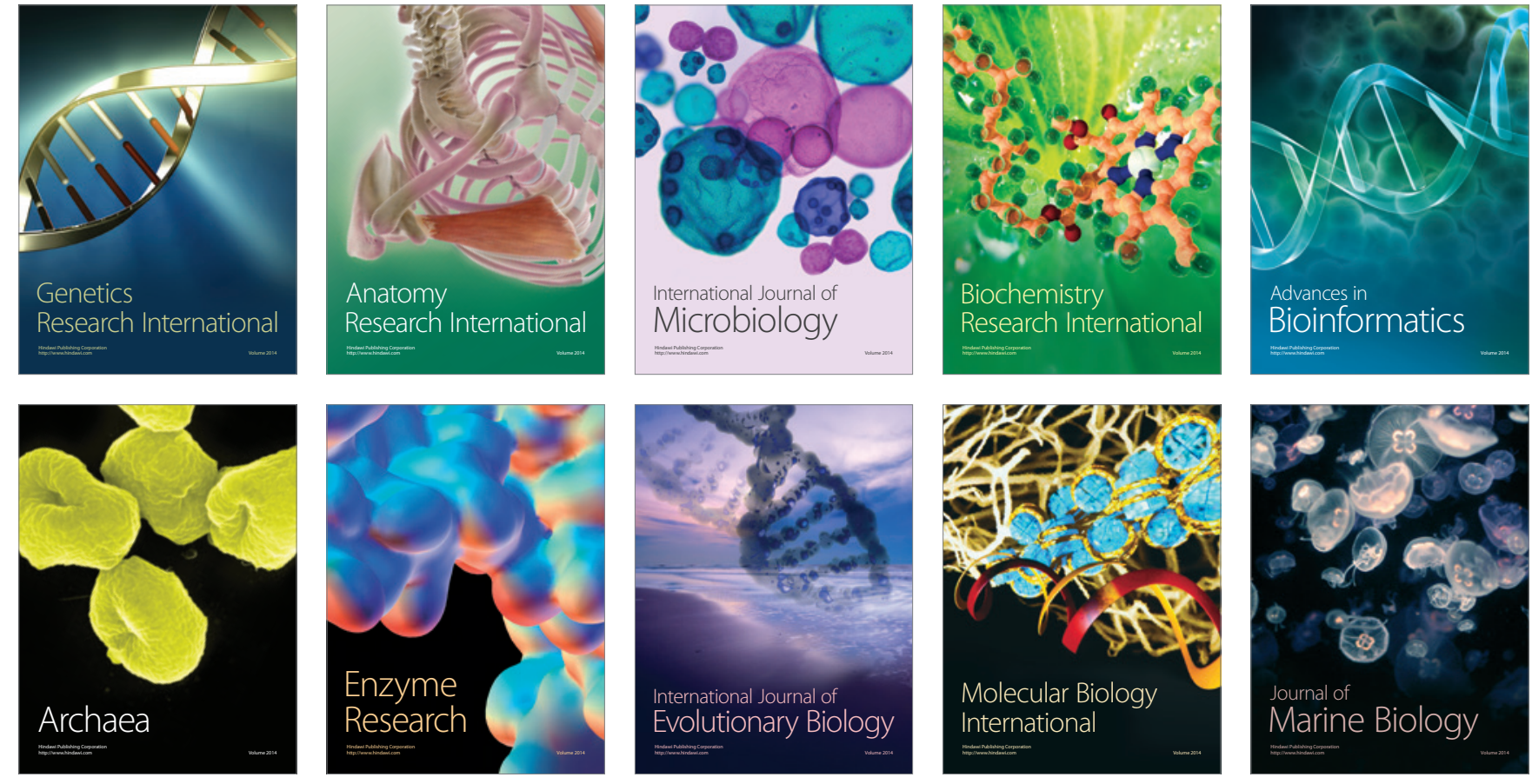